\title{
Traduções
}

\section{Sócrates não Gostava do Método de Estudo de Casos: Por Que Você Gostaria?*}

\author{
Bent Flyvbjerg \\ Universidade de Aalborg
}

Por favor concentra toda a tua atenção e dize-me a verdade.

SÓCRATES

O método de estudo de caso visa desenvolver o rico conhecimento do contexto, do envolvimento e da experiência necessários para se tornar um especialista. Por este motivo, o método é mais eficiente como um instrumento de aprendizagem do que métodos didáticos voltados para a teoria de Sócrates-Platão baseada em regras. Neste artigo argumentamos que somente o conhecimento detalhado de casos torna possível a ascensão de principiante para especialista. A teoria é, geralmente, importante para a educação profissional e prática, mas se as pessoas fossem treinadas exclusivamente através de regras e conhecimentos independentemente do contexto, elas sempre seriam principiantes — saberiam somente as respostas dos livros e funcionariam como computadores ou como burocratas, mecanicamente.

Por que o método de estudo de casos continua a ser tão polêmico? Por que o método é tão eficiente como instrumento didático quanto é

\footnotetext{
- Agradeço ao professor C. Roland Christensen, da Harvard Business School, e ao professor Jose A. Gomez-lbanez, da John F. Kennedy School of Government, Universidade de Harvard, o convite para visitar Harvard, possibilitando que eu estudasse
} 
polêmico? Um crítico do metódo de estudo de casos descreveu-o da seguinte maneira:

É um piscar de olhos de caos intelectual e tão maldita mente ineficiente! Por que deixar uma turma "investigando" uma questão por uma hora se eu posso explicá-la em alguns minutos? Chamam a isso de ensinar?" (Chrístensen, Hansen, 1987, p.31).

Outro disse:

Da forma como eu vejo, o trabalho do professor é dar um sinal inteligível de aprovação ou desaprovação, fazer algumas perguntas, e lançar uma afirmação conclusiva" (idem, p.30).

Por que o método de estudo de caso levanta críticas duras como estas? Por que o método dá início ao que o filósofo Richard J. Bernstein (1985) chama de "ansiedade cartesiana" que é, por exemplo, o medo de cair no vácuo nihilista sem o racionalismo terra firma, que foi tipicamente identificado por René Descartes, e que nos leva de volta a Sócrates e Platão? O método filosofia, da ciência e da sociedade moderna ocidental debilitando o racionalismo tradicional de mais de 2 mil anos.

o método de estudo de caso em ação e participasse do seminário com o professor Chrístensen sobre este assunto. Também desejo agradecer ao professor Louis B. Barnes, da Escola de Administração de Harvard, e a John Boeher, diretor do Centro de Ensino e Aprendizagem Danforlh, da Universidade de Harvard, e aos vários membros do corpo docente e alunos que se dispuseram a discutir o método comigo durante a minha estadia em Harvard. Finalmente, eu agradeço aos professores Hubert e Stuart Dreyfus, do Departamento de Filosofia e do Departamento de Engenharia Industrial e Pesquisas Operacionais, respectivamente, da Universidade da Califórnia, em Berkley, por participarem em conversas elucidativas sobre o seu modelo dos cinco passos na aquisição de uma habilidade. Qualquer pessoa que esteja familiarizada com os trabalhos de C, Roland Chrístensen, Hubert e Stuart Dreyfus irá notar as suas influências neste artigo. Este trabalho foi apoiado pela Danish Social Science Research Council. 


\section{Sócrates e os casos}

Os diálogos de Platão descrevem a busca persistente, mas futil, de Sócrates pela verdade absoluta e pelo conhecimento universal. Como se sabe, Sócrates passou grande parte de sua vida andando pelas ruas de Atenas conversando com artesãos, professores, sábios, poetas, adivinhos, oficiais e cidadãos de todos os tipos.

Sócrates os questionava a respeito dos universais de suas especialidades. Mas, freqüentemente, para seu descontentamento, as respostas eram formadas por exemplos específicos, em lugar dos princípios gerais que ele buscava. Sócrates não continha o seu famoso sarcasmo e perspicácia ao rejeitar os exemplos e insistir que "tinha que haver" simples universais por trás dessa multiplicidade de casos.

No diálogo Menon, Sócrates tenta chegar a uma definição genérica da virtude e do que governa os atos virtuosos. Mas Menon, um sofista e professor, se limita a relatar para Sócrates casos de virtude. Segue-se a transcrição, já que o ponto de vista, expresso há mais de 2 mil anos nesta conversa, continua a influenciar o modo como algumas pessoas vêem o método de estudo de casos:

\footnotetext{
Sócrates - ...Pelos deuses Menon, sé generoso e dize-me o que é a virtude...

Menon - Não será difícil responder à tua pergunta, Sócrates. Primeiramente, consideremos a virtude do homem - ele deve saber administrar o Estado e ao administrá-lo, beneficiar os seus amigos e prejudicar os seus adversários, além de ter muito cuidado para não prejudicar a si mesmo. Cada idade, condição de vida, jovem ou idoso, homem ou mulher, escravo ou livre tem uma virtude diferente: há inumeráveis virtudes e não faltam definições delas; pois a virtude é relativa às ações e à idade de cada um de nós em tudo o que fazemos. E o mesmo pode ser dito com relação ao vício, Sócrates. Sócrates - Como sou feliz, Menon! Quando te indago com relação
}

Versão dos excertos dos diálogos platônicos, s partir da tradução em inglês, da edição norte-americana referida pelo autor: José Adelmo Guimarães. 
a uma virtude; apresentas-me uma multidão delas que estão em tua observação. Suponhamos que aceite a idéia da multidão e te indague qual é a natureza da abelha, e tua resposta a de que há muitas espécies de abelhas e eu responda: Mas as abelhas se diferenciam como abelhas porque há entre elas muitas e diferentes espécies, ou melhor, não podem ser distinguidas por alguma outra qualidade? Aplicando o mesmo raciocínio, ainda que muitas e diferentes, todas têm uma natureza comum que as torna virtude: e a este respeito quem poderia responder à questão o que é virtude? Faria bem ter teus olhos bem atentos, compreendes?... Menon — Tens uma definição de todas elas? Sócrates - É o que estou procurando.

Menon - Sc quiseres uma definição de todas, eu não sei o que dizer, mas virtude é o poder de governar a humanidade... Sócrates — ...mas tu não acrescentas nem "justa" nem "injustamente"?

Menon - Sim, Sócrates, concordo com isto, pois a justiça é virtude.

Sócrates - — Tu, Menon, dirias "virtude" ou "uma virtude"? Menon — O que queres dizer?

Sócrates - Eu entendo o que posso dizer acerca de tudo; que o redondo, por exemplo, é uma figura c não simplesmente 'uma figura' c adotaria este modo de falar, porque há outras figuras. Menon Perfeitamente; c é isto exatamente o que estou dizendo a respeito de virtude - que há outras virtudes como a justiça... A coragem, a temperança, a sabedoria c a magnanimidade são virtudes; c muitas outras mais.

Sócrates - Sim, Menon, permanecemos no mesmo ponto: na busca de uma virtude, encontramos diversas... Não entendes que estou $\mathrm{cm}$ busca do símile in multisl ... Cumpre tua promessa dizendo-me o que é virtude no plano universal? (The Duilogues of Plato, 1986, p.196202).

Da mesma forma, em Eutifron, Sócrates tenta definir o que é sagrado:

Sócrates - Dize-me como defines o sagrado c o que não c sagrado? Eutifron - Bem, eu diria que o sagrado é o que estou fazendo ago$r a$, acusando o homicídio, o roubo do templo e fatos semelhantes... Sócrates - Lembra-te que não te pedi para nie ensinares sobre uma 
ou duas entre muitas coisas que são sagradas, mas acerca daquela característica mesmo pela qual todas as coisas sagradas são sagradas... Dize-me qual é mesmo esta verdadeira característica, para que possa considerá-la e usá-la como um padrão e possa dizer que uma ação semelhante a este padrão praticada por ti ou outro é sagrada ou negála, se lhe não assemelhe. (The Dialogues of Plato, 1986, p.48-50).

Como Menon, Eutifron dá a Sócrates casos concretos e não somente a definição universal desejada. Por este motivo, o argumento fica tautológico com Eutifron refugiando-se da lógica de Sócrates:

Sócrates - Recomecemos desde o início e perguntemos o que é sagrado. Pois, de bom grado, eu não me renderei, antes que aprenda. Por favor, não me menosprezes: aplica toda tua atenção e dize-me agora a verdade.

Eutifron - Numa outra ocasião, Sócrates. No momento eu tenho pressa e já estou atrasado.

Sócrates - O que estas fazendo, amigo? Deixas-me tirando toda a minha grande esperança? (The Dialogues of Plato, 1986, p.61).

\section{A mudança de Platão}

Sócrates encontrou o mesmo problema repetidamente em suas andanças por Atenas. Conseqüentemente, com um impressionante desdém pelo concreto, pelo conhecimento prático, ele chegou a sua famosa conclusão de que ninguém sabia nada, inclusive ele próprio, que, no mínimo, sabia que não sabia nada.

Sócrates estava enganado, é claro. Ele sabia muito. Essa é uma das razões da sua abordagem ter se tornado um marco para a filosofia e a ciência ocidental por mais de 2 mil anos. Assim, Sócrates, que originalmente havia se colocado ao lado da racionalidade analítica, veio a questionar essa mesma racionalidade.

Não é primordialmente por este motivo que Sócrates é lembrado até hoje. 
Outra interpretação de Sócrates, a do seu aluno Platão, tornou-se peremptória. Platão não aceitava a conclusão de Sócrates. Dando continuidade à busca de Sócrates pelos universais, Platão tornou-se o virtual fundador da filosofia e da ciência ocidental. Tendo a matemática como seu ideal, Platão pensou na possibilidade de construir sistemas globais de princípios teóricos objetivos que pudessem ser comprovados racionalmente e fossem utilizados para explicar a natureza e a atividade humana.

Mais tarde Galilei mostrou que as idéias de Platão estavam parcialmente corretas - elas trabalhavam para a natureza. Desse modo, Galilei colocou a ciência natural em seu curso revolucionário.

Não ocorreu um desenvolvimento similar nas ciências sociais. Não houve nenhuma brecha epistemológica para estas ciências e não há indício de que o modelo da ciência natural irá jamais funcionar para as ciências sociais (Dreyfus, 1982). Para se ter uma idéia, apesar de dois séculos de tentativas, as ciências sociais não obtiveram o mesmo sucesso na produção de teorias prognósticas que as ciências naturais conseguiram. Contudo, sustentado pelo sucesso das ciências naturais, o tradicionalismo de Sócrates e Platão e o modelo da ciência natural como um ideal estão presentes - para não dizer que são dominantes - nas ciências sociais, inclusive nas "ciências" educacionais e na prática profissional. O Prêmio Nobel e demais reconhecimentos incentivam primordialmente este ideal.

Dessa forma, não é nenhuma surpresa que o método de estudo de caso seja altamente polêmico. O método produz precisamente o tipo de conhecimento específico, prático e dependente do contexo que Sócrates rejeitou com desprezo. O símile in multis que Sócrates exigiu de Menon implica em raciocínio dedutivo e na busca por princípios genéricos em inumeráveis instâncias, não em estudos profundos sobre casos específicos. Ou seja, de acordo com o jargão da ciência social moderna, $\mathrm{N}=$ muitos é preferível a $\mathrm{N}=1$ quando se está seguindo os passos de Sócrates e Platão. Entretanto, a questão é aonde levam esses passos. Devo 
dizer que, quanto à educação profissional e prática, não levam muito longe.

\section{Como as pessoas se tornam especialistas}

Enquanto o modelo Sócrates-Platão funciona na ciência natural, apesar de até mesmo isto estar sendo questionado atualmente, o modelo falha na educação profissional e prática. Para entender isso, vamos analisar brevemente um relato fenomenológico recente de aquisição de habilidades desenvolvido por Hubert e Stuart Dreyfus (Dreyfus, Dreyfus, Athanasiou, 1986). Dreyfus e Dreyfus distinguiram cinco estágios, de principiante a especialista, na educação do adulto.

\section{PRINCIPIANTE}

De acordo com Dreyfus e Dreyfus, o ensino normalmente começa com o professor descrevendo a tarefa e seu meio com características livres de contexto, as quais os principiantes podem reconhecer sem o benefício da experiência. Então, fornecem-se aos principiantes regras que determinam ações baseadas nestes aspectos, como um computador seguindo um programa. Desprovidos de qualquer relação coerente entre a tarefa e o todo, eles julgam o seu próprio desempenho baseados principalmente em como conseguem seguir as regras ensinadas. Depois de terem adquirido algumas regras, os principiantes demandam tanta concentração durante a execução da habilidade adquirida que a sua própria capacidade de falar ou ouvir uma recomendação fica seriamente limitada.

O principiante na auto-escola aprende a reconhecer algumas características livres de interpretação, como a velocidade (indicada pelo velocímetro) e a distância (estimada por uma habilidade adquirida previamente). As distâncias para seguir com segurança são definidas em 
termos de velocidade; as condições que permitem entrar com segurança no tráfego são definidas em termos de velocidade e distância dos carros no mesmo sentido; mudanças de marcha são especificadas em termos de velocidade, etc. Estas regras ignoram o contexto tais como a densidade do tráfego e a previsão das paradas que serão feitas.

\section{INICIANTE AVANÇADO}

De acordo com Dreyfus e Dreyfus, os principiantes ganham realmente experiência lidando com situações reais. Os principiantes começam a notar, ou os professores apontam exemplos, ou casos, de componentes adicionais significativos da situação. Depois de verem um número suficiente de casos, os estudantes aprendem a reconhecê-los. Agora, os princípios da aprendizagem podem se referir a estes novos aspectos situacionais reconhecidos com base na experiência, assim como aos aspectos definidos objetivamente como não-situacionais pelo principiante. Os iniciantes avançados confrontam o meio, procuram características e aspectos, e determinam as suas ações, aplicando as regras. Compartilhando do interesse mínimo que o principiante tem com a qualidade de desempenho, os iniciantes também focalizam a qualidade da regra a seguir. O desempenho do iniciante avançado melhora, mas permanece devagar, descoordenado e trabalhoso.

Os motoristas iniciantes avançados usam o som do motor (situacional) tanto quanto a velocidade na mudança das marchas (não-situacional), e observam a conduta, assim como a posição e a velocidade, para prever o comportamento de pedestres ou de outros motoristas. Eles aprendem a distinguir entre o comportamento de um motorista bêbado e de um motorista impaciente, mas alerta. Nenhuma quantidade de palavras pode substituirá função de alguns exemplos dados para ensinar esta distinção. O som dos motores não pode ser captado adequadamente por palavras. Nenhuma lista de fatos objetivos a respeito de um pedestre 
especifico pode prever seu comportamento ao atravessar uma rua tão bem quanto um motorista que tenha observado muitos pedestres atravessando a rua em uma diversidade de condições.

\section{COMPETÊNCIA}

Com o acúmulo de experiência, a quantidade de características e aspectos a serem considerados torna-se esmagadora. Para lidar com esta explosão de informações, os alunos aprendem, ou são ensinados, a adotar uma visão hierárquica para a tomada de decisão. Os alunos podem simplificar ou implementar o desempenho escolhendo primeiro um plano, objetivo ou perspectiva para, então, organizar a situação e examinar somente uma parcela das características e aspectos que eles aprenderam, que são os mais importantes em dada perspectiva. Escolher um plano, objetivo ou perspectiva não é uma tarefa simples para alunos competentes, de acordo com Dreyfus e Dreyfus. Eles têm expectativas quanto ao modo como as coisas vão acontecer, mas, geralmente, ficam surpreendidos quando estas expectativas não são preenchidas. Ninguém pode fornecer regras de como escolher uma perspectiva; por isso, os competentes precisam criar várias regras próprias, que podem ser adotadas ou descartadas em várias situações, dependendo da sua eficácia. Todavia, esta escolha é inevitável. Enquanto os iniciantes avançados podem obter êxito sem usar um aspecto situacional específico, até que um número suficiente de exemplos torne a identificação fácil e correta, o desempenho competente requer a escolha de objetivos ou perspectivas organizados. Além disso, a escolha de uma perspectiva afeta crucialmente o comportamento, o que raramente acontece com um aspecto específico. Esta combinação de necessidade com incerteza introduz um novo tipo de relacionamento importante entre os alunos e o meio. $\mathrm{O}$ principiante e o iniciante avançado, aplicando as regras e os princípios, sentem pouca ou nenhuma responsabilidade pelo resultado de seus atos. 
Se eles não tiverem cometido algum erro, um resultado mal-sucedido é visto como conseqüência de elementos ou regras especificadas inadequadamente. Os competentes, por outro lado, depois de lutarem com a questão da escolha de perspectiva ou objetivo, sentem-se responsáveis e, portanto, emocionalmente envolvidos pelo resultado de sua escolha. Um resultado claramente bem-sucedido é profundamente satisfatório e deixa uma lembrança vivida da situação, da forma como ela é vista do objetivo ou da perspectiva finalmente escolhido. Os desastres, outrossim, não são esquecidos facilmente.

\section{PROFICIÊNCIA}

Dreyfus e Dreyfus explicam que uma experiência considerável no nível de competência propicia o aprimoramento da habilidade. Tendo experimentado situações variadas, escolhido planos em cada uma, ou tendo experimentado vividas e envolventes demonstrações de adequação ou inadequação destes planos, os alunos envolvidos no mundo da sua habilidade "reparam" ou "são acordados" por um determinado plano, objetivo ou perspectiva. $\mathrm{O}$ encantamento do envolvimento não será mais quebrado pelo planejamento consciente separadamente.

Já que comumente há muito menos "formas de ver" do que "formas de agir", depois de compreender sem um esforço consciente o que está acontecendo, os alunos proficientes ainda terão que pensar no que fazer. Durante esta reflexão, os elementos proeminentes são calculados e combinados através de regras para produzir decisões sobre a melhor forma de manipular o meio. O encantamento do envolvimento no mundo da sua atividade será então temporariamente quebrado.

5. EsPeCIALISTA

O aluno proficiente, imerso no mundo de sua atividade, vê o que precisa ser feito e decide como fazê-lo. Com experiência suficiente 
adquirida através da variedade de situações vistas de uma mesma perspectiva (com o mesmo objetivo, significado, tema), mas requerendo diferentes decisões táticas, o aluno proficiente decompõe gradualmente esta classe de situações em subclasses, cada uma das quais compartilha a mesma decisão, ação ou tática. Isto permite uma resposta intuitiva imediata para cada situação, que é a característica do especialista.

A quantidade de classes de situações distintas construídas com base na experiência é imensa, segundo Dreyfus e Dreyfus. Foi estimado que um jogador de xadrez profissional consegue distinguir perto de $50 \mathrm{mil}$ tipos de posições. A condução de automóveis provavelmente requer a habilidade de discriminar um número similar de situações. Estas classes distintas de estímulos, ao contrário dos elementos situacionais aprendidos por iniciantes avançados, não têm nome e, de fato, não comportam descrições verbais conclusivas.

Enquanto os alunos proficientes precisam estar cientes da importância da situação para decidir o que fazer, os especialistas, somente algumas vezes, estão cientes da importância da situação. Em atividades tais como artes marciais, basquetebol e tênis, assim como nas situações sociais cotidianas, os especialistas não têm nem tempo para ponderar. A qualidade do especialista, então, depende da sutileza dos diferentes tipos de situações que a mente pode discriminar apropriadamente. Cada tipo de situação pede um tipo apropriado de resposta. O que precisa ser feito é feito transparentemente.

Em outros tipos de atividade, como administração de empresas, conferências de imprensa, esportes como golfe e boliche, e torneios de xadrez, há tempo para ponderar. A ponderação acontece em dois tipos de situação. No primeiro, o mesmo estímulo impele em diferentes gestalts, por exemplo, sob várias perspectivas diferentes. Os especialistas precisam decidir o que ver como problema. Comumente, embora não crucialmente, o problema está claro, mas há mais de uma resposta atraente e os especialistas precisam decidir o que fazer. Em ambos os casos, é necessária a ponderação. Portanto, os especialistas usam técnicas tais 
como recolher mais informações para decidir entre interpretações e atitudes plausíveis que são quase semelhantes. Se os especialistas tiverem passado por experiências suficientes, a simples escolha do que lhes parece melhor, sem se importarem com as pequenas diferenças, normalmente produzem desempenhos de alta qualidade. Dessa forma, esses tipos de decisão ponderativa determinam quem chega ao topo.

Motoristas experientes sabem insconscientemente, não só por sentirem e estarem familiarizados com situações, como a necessidade de reduzir a velocidade, por exemplo, como fazê-lo sem ter que calcular oú comparar alternativas. Eles mudam de marcha apropriadamente sem estarem cientes dessa atitude. Grande parte dos motoristas já passou pela situação de desorientação quando, inesperadamente, pensam no processo de mudança de marcha e têm que decidir o que fazer. Repentinamente, a seqüência de ações quase automática resultante da imersão do especialistas no mundo de sua habilidade é quebrada, e eles se vêem, assim como iniciantes competentes, como manipuladores de um mecanismo complexo. Os especialistas calculam separadamente suas ações ainda mais pobremente do que iniciantes competentes, uma vez que os especialistas já esqueceram muitas das regras pelas quais se guiavam quando eram iniciantes, e seu desempenho se torna subitamente lento, incerto e, até mesmo, inapropriado. Isto pode acontecer com um motorista experiente em seu país que dirija, pela primeira vez, em um país estrangeiro com o tráfego na direção oposta, por exemplo.

Um iniciante parece fazer deduções utilizando as regras e os fatos como um computador programado heuristicamente, mas com talento, envolvimento e experiência, o iniciante desenvolve-se ao ponto de especialista que, intuitivamente, vê o que deve ser feito sem a necessidade de aplicar regras.

\section{A força do método de estudo de casos}

O modelo de Dreyfus tem certas limitações como um modelo geral de aprendizagem. No meu entender, a criatividade e a inovação não são 
adequadamente abordadas ${ }^{1}$. Entretanto, esta crítica não é importante para a compreensão específica do método de estudo de caso em relação ao modelo. A questão importante aqui é a reivindicação minimalista do modelo, de que há um salto qualitativo do comportamento dos iniciantes, baseado em regras e independente do contexto para o comportamento do especialista, que é baseado na experiência e depende do contexto. .

O método de estudo de caso visa diretamente ao desenvolvimento do rico conhecimento do contexto, do envolvimento e da experiência necessários para se tornar um especialista. Esta é a razão de o método ser mais eficiente como um instrumento de aprendizagem do que métodos didáticos voltados para a teoria de Sócrates-Platão, baseada em regras. Argumentamos que somente o conhecimento detalhado de casos torna possível a ascensão dos primeiros para os últimos estágios do processo de aprendizagem.

Se as pessoas fossem treinadas exclusivamente através de regras e conhecimentos independentemente do contexto, elas seriam eternamente principiantes - saberiam somente as respostas dos livros e funcionariam como computadores ou como burocratas, mecanicamente. Esta é a ironia e a limitação da racionalidade analítica de Sócrates-Platão. Ela é cruamente insuficiente para o desempenho profissional no nível de especialista. E um erro cometido regularmente deixar que a tradição de Sócrates-Platão domine a educação profissional e prática ${ }^{2}$.

Conclui-se que, no âmbito da educação profissional e prática, a resposta que Eutífron deu a Sócrates, quando este insistiu em obter a verdade absoluta e os critérios universais, ainda pode ser a melhor resposta para os Sócrates e Platões de nossos dias: "Será para outra vez, Sócrates".

\footnotetext{
' Desenvolvi este e outros pontos da apreciação considerando o modelo de Dreyfus em uma crítica favorável ao modelo (cf. Flyvbjerg, 1989)

${ }^{1}$ Com relação ao caso da engenharia, cf. Keer, Byron, 1987).
} 


\section{Referências bibliográficas}

BERNSTEIN, Richard J. Beyond objectivism and relativism: science, hermeneuties, and praxis. Philadelphia: University of Pennsylvania Press, 1985.

CHRISTENSEN, Roland, HANSEN, Abby J. Teaching and the case method. Boston: Harvard Business School Press, 1987. cap.: Theaching with cases at the Harvard Business School.

DREYFUS, Hubert. Why studies of human capacities modeled on ideal natural science can never achieve their goal. Boston: Colloquium for the Philosophy of Science, Oct. 1982.

DREYFUS, Hubert, DREYFUS, Stuart, ATHANASIOU, Tom. Mind over machine: the power of humam intuition and expertisie in lhe era of the computer. New York: Free Press, 1986.

FLYVBJERG, Bent. Analysis and intuition in learning: an evaluation of the Hubert and Stuart Dreyfus Model of skill acquisition: research report. Denmark: University of Aalborg, Institute of Development and Planning, 1989.

KERR, Arnold D., PIPES, R. Byron. Why we need hands: on engineering education. Thechnology Review, v.90, n.7, 1987.

PLATÃO. The dialogues. New York: Bantam, 1986.

Recebido em 14 de outubro de 1993.

Bent Flyvberg, Ph.D. é professor-adjunto de Planejamento na Universidade de Aalborg, na Dinamarca, e foi por duas vezes professor visitante nos Estados Unidos, patrocinado pela Comissão Fulbright. 